\title{
Modulation of Calcium-activated Chloride Current via pH-induced Changes of Calcium Channel Properties in Cone Photoreceptors
}

\author{
Steven Barnes and Quynh Bui \\ Department of Medical Physiology, Faculty of Medicine, University of Calgary, Calgary, Alberta, Canada T2N 4N1
}

The activity of calcium-activated chloride channels is controlled through the complex interaction of cellular mechanisms affecting calcium entry, buffering, and extrusion, and an unknown stoichiometric relation between intracellular $\mathrm{Ca}$ concentration and $\mathrm{Cl}$ channel activation. Here, we show that calcium-activated chloride current $\left[I_{\mathrm{Cl}(\mathrm{Ca})}\right]$ in cone photoreceptors is also highly sensitive to external pH, being strongly reduced by acidification and enhanced by alkylinization of the bathing medium. We propose that this modulation is accounted for by the $\mathrm{pH}$ sensitivity of Ca channel activation and permeation, already well characterized in other cells, which we now extend to cone photoreceptor $\mathrm{Ca}$ channels. Acidification of the external medium from a control pH of 7.4 shifts the $\mathrm{Ca}$ channel activation range positively by about $10 \mathrm{mV}$ at $\mathrm{pH} \mathrm{6.8,} \mathrm{reducing} \mathrm{the} \mathrm{magnitude} \mathrm{of} \mathrm{calcium} \mathrm{current}$ with a consequent reduction of chloride current. Alkylinization shifts the $\mathrm{Ca}$ channel activation range negatively by about $8 \mathrm{mV}$ at pH 8 and produces larger calcium currents during step depolarizations that in turn elicit larger chloride tail currents. Modulation of $I_{\mathrm{CI}\left(\mathrm{Ca}_{\mathrm{s}}\right)}$ by $\mathrm{pH}$ suggests other consequences of the $\mathrm{pH}$-induced shift in $\mathrm{Ca}$ channel gating, for one, modification of $\mathrm{Ca}$-dependent transmitter release, which could be especially significant in photoreceptors where the cell's operating voltage range overlaps only the lower end of the Ca channel activation range.

One feature of calcium-activated chloride channels is a strong intrinsic dependence on intracellular calcium ([Ca $]_{i}$ ), rather than membrane potential, for channel gating (Evans and Marty, 1986). In this respect, they are unlike some calcium-activated potassium channels for which intracellular calcium sets the range over which strong voltage-dependent gating occurs (Barrett et al., 1982). This feature makes calcium-activated chloride channels more like some ligand-gated channels, whose gating depends entirely on the presence of an intracellular messenger (e.g., the cGMP-gated channel of photoreceptors) or a neurotransmitter agonist (e.g., the nicotinic ACh-receptor channel). The dominant dependence of $I_{\mathrm{CI}(\mathrm{Ca})}$ on calcium has been exploited, for example,

\footnotetext{
Received Apr. 15, 1991; revised July 1, 1991; accepted July 31, 1991.

We thank S. Eliasof, P. Lukasiewicz, and J. Kleinschmidt for discussions regarding the $\mathrm{Ca}$ channel activation range in photoreceptors, and $\mathrm{L}$. Haynes and $W$. Wonderlin for comments on the manuscript. This work was supported by the Alberta Heritage Foundation for Medical Research (AHFMR) and the Medical Research Council of Canada (MRC). S.B. is an AHFMR and MRC scholar.

Correspondence should be addressed to Steven Barnes, Ph.D. Department of Medical Physiology, Faculty of Medicine, University of Calgary, Calgary, Alberta, Canada $\mathrm{T} 2 \mathrm{~N} 4 \mathrm{~N} 1$.

Copyright (c) 1991 Society for Neuroscience $0270-6474 / 91 / 114015-09 \$ 05.00 / 0$
}

to study the time course of reduction of $[\mathrm{Ca}]_{i}$ following step depolarizations that evoke calcium influx (Korn and Horn, 1989).

A steep dependence of calcium-activated chloride tail current on extracellular $\mathrm{pH}$ has also been reported in voltage-clamped cone photoreceptors (Barnes and Hille, 1989). $I_{\mathrm{Cl}(\mathrm{Ca})}$ tails, recorded at $-40 \mathrm{mV}$ and evoked by depolarizing test steps that opcned L-type calcium channels, disappeared when the bath $\mathrm{pH}$ was reduced from 7.4 to 7.0 and increased markedly when the bath $\mathrm{pH}$ was increased to 7.8 . It seemed reasonable that protons (or hydroxyl ions) could interact with the $\mathrm{Cl}$ channel and modify its gating behavior and/or permeability. Other $\mathrm{Cl}$ channels, insensitive to calcium, exhibit pronounced sensitivity to $\mathrm{pH}$. For example, the chloride conductance of frog skeletal muscle is a steep, sigmoidal function of external pH (Hutter and Warner, 1967), and the weakly voltage-dependent $\mathrm{Cl}$ channels of lobster nerve are irreversibly suppressed by acidification of the cytoplasmic solution to pH 6.0 (Lukacs and Moczydlowski, 1990).

Protons might also influence $\mathrm{Ca}$-activated $\mathrm{Cl}$ channel activity via effects on Ca channels. Considerable evidence from a variety of other preparations has shown Ca channels to be sensitive to $\mathrm{pH}$, demonstrated primarily by shifts along the voltage axis of the channel's activation curve, as well as changes in channel conductance (Ohmori and Yoshii, 1977; Iijima et al., 1986; Kaibara and Kameyama, 1988; Krafte and Kass, 1988; Prod'hom et al., 1989), which might account for the modulation of $I_{\mathrm{Cl}(\mathrm{Ca})}$ in cones.

The goal of the present work was to measure the $\mathrm{pH}$ dependence of $I_{\mathrm{C}(\mathrm{Ca})}$ and to determine to what extent modulation of $I_{\mathrm{Cl}(\mathrm{Ca})}$ by $\mathrm{pH}$ involved $\mathrm{pH}$-dependent changes in the gating and/ or permeation of cone $\mathrm{Ca}$ channels and $\mathrm{Cl}$ channels. The action of $\mathrm{pH}$ is expressed primarily as a change in the time course of chloride tail currents, suggesting either a gating modification intrinsic to the $\mathrm{Cl}$ channel or gating changes due to alterations of $[\mathrm{Ca}]_{i}$ underlaid by $\mathrm{Ca}$ channel modifications. We show that cone $\mathrm{Ca}$ channels are sensitive to $\mathrm{pH}$ (as are other $\mathrm{Ca}$ channels) and argue that this alone could account for most of the observed effects of $\mathrm{pH}$ on cone $I_{\mathrm{Cl}(\mathrm{Ca})}$.

A preliminary report of these findings has been published previously (Barnes and Bui, 1990).

\section{Materials and Methods}

Isolation of cones. Larval tiger salamanders, Ambystoma tigrinum (Kons Scientific Supply, Germantown, WI), were stored at $5^{\circ} \mathrm{C}$ under an 8:16 hr light: dark cycle. For 1-3 d prior to use, they were kept in a cool tank $\left(10-13^{\circ} \mathrm{C}\right)$ with the same light cycle. After animals were decapitated and pithed, an eye was enucleated, its cornea and lens were removed, and the retina was pulled out. The other eye was enucleated and stored in bath solution in darkness at $5^{\circ} \mathrm{C}$ for later use. Isolated retinas were incubated at about $28^{\circ} \mathrm{C}$ for $15 \mathrm{~min}$ in $0.5 \mathrm{mg} / \mathrm{ml}$ papain (type IV, Sigma Chemical Co., St. Louis, MO) dissolved in standard bath solution. They 
were rinsed for several minutes in standard bath solution and triturated, and the resulting cell suspension was placed in $200-500 \mathrm{ml}$ wells formed with Sylgard 182 (Dow Corning, Midland, MI) in $35 \mathrm{~mm}$ plastic Petri dishes or on glass slides. Recordings were made from both single and double cones. Throughout the course of each experiment, the cells were brightly illuminated by the $50 \mathrm{~W}$ microscope lamp supplied with about $6 \mathrm{~V}$, which likely eliminated most current contributions from ion channels in the outer segment. Similar results were obtained from cones with and without outer segments.

Solutions. The standard bath solution contained $90 \mathrm{~mm} \mathrm{NaCl}, 2.5$ $\mathrm{mm} \mathrm{KCl}, 3 \mathrm{~mm} \mathrm{CaCl}, 8 \mathrm{~mm}$ glucose, and $10 \mathrm{~mm}$ HEPES, titrated to pH 7.4 with $\mathrm{NaOH}$. To examine $\mathrm{Ca}$ channel activation, 10 or $20 \mathrm{~mm}$ $\mathrm{BaCl}_{2}$ replaced $3 \mathrm{mM} \mathrm{CaCl}_{2}$, and $30 \mathrm{mM} \mathrm{TEA} \mathrm{Br}$ replaced an equivalent amount of $\mathrm{NaCl}$. The $\mathrm{pH}$ of each solution was measured before each experiment with a $\mathrm{pH}$ meter (Corning model 240) and adjusted with $\mathrm{NaOH}$ or $\mathrm{HCl}$. Other solution changes are described in the text or figure captions. All recordings described here were made with a whole-cell pipette solution containing $100 \mathrm{~mm} \mathrm{CsCl,} 3.5 \mathrm{mM} \mathrm{MgCl}_{2}, 1 \mathrm{~mm}$ EGTA, $1.5 \mathrm{~mm} \mathrm{Na}_{3}$-ATP, and $10 \mathrm{~mm}$ HEPES, titrated to $\mathrm{pH} 7.2$ with $\mathrm{NaOH}$. ATP, EGTA, and HEPES were obtained from Sigma (St. Louis, MO) Solutions were applied at room temperature (between $21^{\circ} \mathrm{C}$ and $25^{\circ} \mathrm{C}$ ) by gravity-driven inflow via an eight-way valve and removal by a reversed aquarium air pump.

Whole-cell recording and analysis. Whole-cell pipettes were pulled from glass hematocrit tubes (Western Scientific, Richmond, BC) in two steps on a vertical pipette puller (Kopf model 730, Tujunga, CA), coated with Sylgard, and lightly fire polished. Filled with the $\mathrm{CsCl}$ pipette solution, they had tip resistances between 4 and $10 \mathrm{M} \Omega$ measured in the standard bath. The bath reference electrode consisted of a bath solution-filled agar bridge with an $\mathrm{AgCl}$ wire. Whole-cell voltage was clamped with an Axopatch 1-C (Axon Instruments, Burlington, CA) using pipette and whole-cell capacitance compensation to reduce capacitive artifacts as much as possible, but often without series resistance compensation feedback. For chloride current studies, the current signal was filtered at $500 \mathrm{~Hz}(-3 \mathrm{~dB}$, four pole low-pass Bessel) and recorded and stored digitally at $1 \mathrm{kHz}$ (12-bit resolution) with a BASIC-FASTLAB system (Indec Systems, Sunnyvale, CA) incorporating an $80 \mathrm{kHz}$ LabMaster A/D board with opto-isolation and a 386 computer. For barium and calcium current recordings, the signal was filtered at $1 \mathrm{kHz}$ and sampled at $2 \mathrm{kHz}$. BASIC-FASTLAB software also generated the voltage-clamp commands and provided programs for analysis (see below) and plotting of data. Several successive points were averaged together in some records where currents changed slowly in time to reduce storage rcquircments. For illustration, one to three points at the peak of each capacitance current transient have been removed from some records.

Pipette and bath electrode junction potentials were measured against high-resistance (50-200 M 2$) 3 \mathrm{~m} \mathrm{KCl}$ electrodes. Pipette potentials were about $2 \mathrm{mV}$ for the $\mathrm{CsCl}$ pipette/ $\mathrm{NaCl}$ bath combination and about 4 $\mathrm{mV}$ for the $\mathrm{CsCl}$ pipette/Ba-TEA bath combination. Reported voltages are uncorrected for these errors; however, most of the conclusions of this work are drawn from voltage shifts, not the voltages themselves. Changes of bath $\mathrm{pH}$ had no effect on the junction potential at the bath electrode.

Curve fitting. Activation curves derived from $\mathrm{Ba}$ or $\mathrm{Ca}$ current-voltage $(I-V)$ relations or from $\mathrm{Cl}$ tail current charge-voltage $(Q-V)$ relations are characterized by the midpoint and slope factor of the least squaresfitted Boltzmann relation, given by

$$
a=\left(1+\exp \left[\left(V-V_{\text {mid }} / m\right]\right)^{-1},\right.
$$

where $V$ is the membrane voltage, $V_{\text {mid }}$ is the midpoint voltage, and $m$ is the slope factor.

For $I-V$ relations, the activation curve was derived by dividing the leak-subtracted $I-V$ relation by the driving force $\left(V-V_{\text {rev }}\right)$ and normalizing. The treatment of $Q-V$ relations was similar except that, since there is no reversal of $Q$ (the integrated $\mathrm{Cl}^{-}$tail current), we first obtained a least-squares-fit line to the descending portion of the $Q-V$ curve (e.g., the section beween +40 and $+80 \mathrm{~V}$ in the curve made at $\mathrm{pH} 7.4$ in Fig. $1 B$ ) and then divided the $Q-V$ relation by this line, generating an activation curve. This line represents the "driving force" and its $\mathrm{x}$-axis intercept is analogous to the reversal potential of a regular $I-V$ relation.

\section{Results}

Results are presented in the following order: (1) introduction of cone $I_{\mathrm{Cl}(\mathrm{Ca})}$ and its modulation by $\mathrm{pH},(2)$ description of $\mathrm{pH}$ sensitivity of cone $\mathrm{Ca}$ channels, and (3) comparison of $\mathrm{pH}$ sensitivity of $I_{\mathrm{Cl}(\mathrm{Ca})}$ with that shown for Ca channels.

\section{Ca-activated chloride current of cone photoreceptors}

We first summarize several properties of $I_{\mathrm{Cl}(\mathrm{Ca})}$ and $I_{\mathrm{Ca}}$ in cone photoreceptors relevant to this study. As Figure $1 A$ shows, small depolarizing test steps applied to an isolated cone may elicit inward currents, while larger test steps elicit outward currents. Inward tail currents first appear following the same voltage step during which inward current during the step was first elicited (in this cell, $-30 \mathrm{mV}$ ). The magnitude and length of the slowly decaying inward tail currents gradually increase as the test step is made more positive and then decrease as the step potential exceeds $+30 \mathrm{mV}$. This result is the same as that of a previous study in cones (Barnes and Hille, 1989), which further demonstrated that the tail currents are carried by $\mathrm{Cl}^{-}$through channels activated by the influx of calcium that occurred during the depolarizing test step.

We estimated the total $I_{\mathrm{Cl}(\mathrm{Ca})}$ tail by integrating each tail current (neglecting the contribution of calcium tail current, which is very small in comparison). We did this because isochronal measurement of the magnitude of $I_{\mathrm{CI}(\mathrm{Ca})}$ tails gave a limited view of tail current decay. Saturation of tail current magnitude often occurred at some potentials while the tail decay was still changing as a function of the prepulse potential (see Figs. $3 A, 5 A$ ). In many cases, $I_{\mathrm{CICa}}$ decay time course continued to lengthen even though current magnitude had reached a maximum. Therefore, a plot of current magnitude against prepulse potential would saturate at a maximum over the same range of potentials where tail integral, containing information about both magnitude and time course, would continue to increase.

The resultant charge-voltage relation always looked somewhat like an inverted calcium current-voltage relation (Fig. $1 B$ ). This shape is characteristic of Ca-activated currents in general, although the relation peaks and declines over a more positive voltage range than do typically measured calcium current-voltage relations. The integrals were all calculated from tails recorded at the same voltage, thereby eliminating possible voltage dependence of $I_{\mathrm{ClCa}}$ as the cause for this shift. Figure $1 C$ further suggests the calcium dependence of $I_{\mathrm{Cl}(\mathrm{Ca})}$. $\mathrm{Cd}^{2+}(100 \mu \mathrm{M})$, a potent blocker of cone Ca channels (Barnes and Hille, 1989), reversibly inhibits the tail currents that follow step depolarizations.

Three additional, time-dependent features of $I_{\mathrm{Ca}}$ and $I_{\mathrm{Cl}(\mathrm{Ca})}$ are important to point out here, as failure to consider them may lead to misinterpretation of $I_{\mathrm{Cl}(\mathrm{Ca})}$ properties. First, repeated depolarizing steps cause tail currents to increase cumulatively or "build-up," as demonstrated in Figure $2 A$, where steps from -60 to $-20 \mathrm{mV}$ were applied every $3 \mathrm{sec}$. This presumably occurs as the result of a local $[\mathrm{Ca}]_{i}$ increase caused by reduced calcium buffering and/or diffusion as repeat episodes of calcium influx, diffusion, and sequestration saturate the available mechanisms for rapidly removing calcium from sites adjacent to the membrane.

Calcium currents do not build up and are therefore not responsible for the increase in $I_{\mathrm{Cl}(\mathrm{Ca})}$. Figure $2 B$ shows a test of whether calcium currents cumulatively increase under these conditions. Here, the chloride equilibrium potential, $E_{\mathrm{Cl}}$, is set near $0 \mathrm{mV}$ because bath and pipette solutions contain nearly equal concentrations of $\mathrm{Cl}^{-}$. During each step to $0 \mathrm{mV}$, little chloride current flows, so a buildup of $I_{\mathrm{Ca}}$, if occurring, should be revealed. Little inward current change is seen during the 


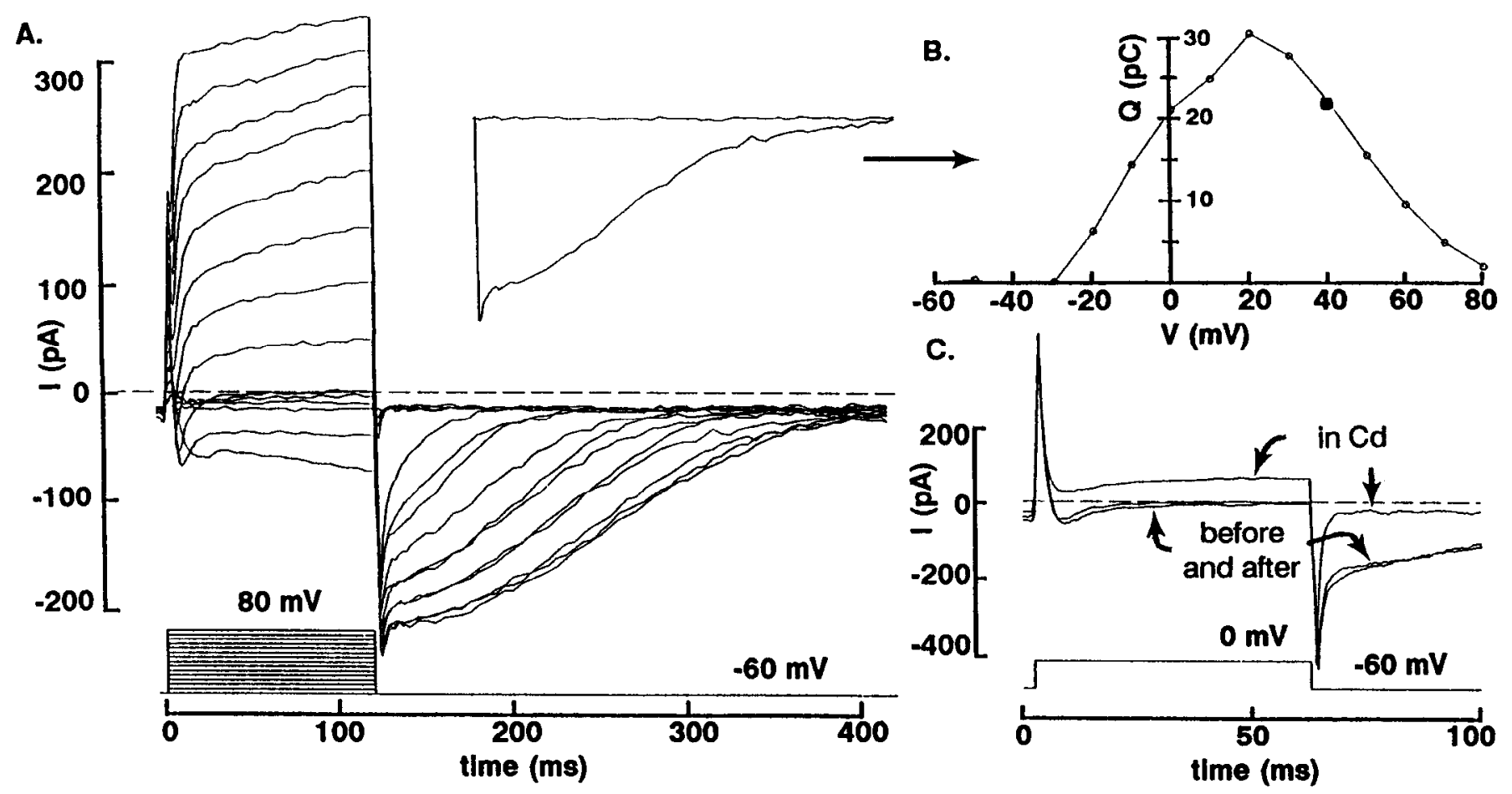

Figure 1. Depolarization-evoked calcium-activated chloride tail currents at pH 7.40 in $3 \mathrm{~mm}$ Ca bath solution. $A$, A cone photoreceptor was held at $-60 \mathrm{mV}$ and depolarized cvery $10 \mathrm{scc}$ in steps lasting $120 \mathrm{mscc}$, cach incremented by $10 \mathrm{mV}$ up to $+80 \mathrm{mV}$. Large, long-lasting tail currents appear following the depolarizing steps to $-20 \mathrm{mV}$ and above. The tail currents following steps to $+10,+20$, and $+30 \mathrm{mV}$ nearly superimpose, while the tails following steps to 0 and $+40 \mathrm{mV}$ share their time course, as do those following -10 and $+50 \mathrm{mV}$. The cell's resting potential can be seen to be positive to $-60 \mathrm{mV}$ because the zero current level, indicated by the broken line, is positive to the holding current trace. The inset (reduced 15\%) shows isolated tail current following step to $+40 \mathrm{mV}$ along with the holding current at $-60 \mathrm{mV}$ to establish a baseline. The area inside the traces was measured digitally by subtracting the integral of the $+40 \mathrm{mV}$ trace from that of the $-60 \mathrm{mV}$ trace and is plotted in $B$ as the large solid symbol. $B$. Chloride charge-voltage relation obtained from integration of chloride tail currents by technique described in $A$. Units of electric charge on the vertical axis are picocoulombs (pC). The solid line connects the dots. $C$, Block by bath superfusion of $100 \mu \mathrm{M} \mathrm{Cd}^{2+}$ and recovery of tail current following step to $0 \mathrm{mV}$. These records include incompletely compensated capacitive artifacts. Details of the recording conditions are described in Materials and Methods.

repeated depolarizations, while the tail current following those steps grows substantially. The experiment further demonstrates the recovery of calcium current (measured during the step at 0 $\mathrm{mV}$ ) and chloride tail current after both had been eliminated with $\mathrm{Cd}^{2+}$. Following removal of the $\mathrm{Cd}^{2+}$, which had blocked $65 \mathrm{pA}$ of calcium current during the steps to $0 \mathrm{mV}$, calcium current slowly returns, but in advance of the recovery of tail current. The slower recovery of tail current suggests the existence of a $[\mathrm{Ca}]_{i}$ threshold that must be exceeded before significant tail currents develop.

Current-voltage (or charge-voltage) relations generated by stepping the membrane to incremented potentials as done in Figure 1 will also be contaminated with buildup if the steps are spaced too closely. In the experiments that follow, measures have been taken to reduce the impact of buildup on tail current measurements. Spacing short depolarizing steps $10 \mathrm{sec}$ apart usually eliminated buildup, probably by allowing recovery of the cell's capability to buffer calcium influx between successive depolarizations. This protocol was followed in experiments in which buildup might lead to misinterpretation of the actions of $\mathrm{pH}$ by shifting the charge-voltage relation and increasing the peak current.

A second time-dependent change is the rundown of both calcium currents and chloride tail currents that occurs with the whole-cell patch technique. In spite of the inclusion of $\mathrm{Mg}^{2+}$ and ATP in the pipette solution, $I_{\mathrm{Ca}}$ and $I_{\mathrm{CKCa}}$ rundown occurred typically over a period of $10-30 \mathrm{~min}$ as illustrated in Figure 2, $C$ and $D$. In some cases, a particularly large calcium influx, accompanied by large chloride tail currents, was followed by complete suppression of tail current availability. Tail current often recovered in minutes following such episodes, but was reduced in amplitude and time course (not shown).

Finally, channel activation curves undergo a slow shift toward more negative potentials, a well-documented dialysis-related event. Such a shift of $I_{\mathrm{Cl}(\mathrm{Ca})}$ activation to more negative potentials is shown in Figure $2 C$. Here, a $14 \mathrm{mV}$ negative shift occurred over a $25 \mathrm{~min}$ time span. Figure $2 D$ shows the shift in the midpoint of $\mathrm{Ca}$ channel activation in a cell from which barium current-voltage relations were obtained for $26 \mathrm{~min}$. The activation curve, derived from the current-voltage relation recorded $2 \mathrm{~min}$ after breakthrough, was well fit by a Boltzmann function with a midpoint of $-19 \mathrm{mV}$, while $24 \mathrm{~min}$ later this value had shifted to $-37 \mathrm{mV}$. In the following experiments in which the bath $\mathrm{pH}$ has been changed, we have minimized the effect of this shift by always bracketing measurement of current-voltage relations obtained in a test $\mathrm{pH}$ with current-voltage relations made at pH 7.4. Usually, the two bracketing measurements yielded nearly the same values for activation midpoint and peak current, but if they differed by $2 \mathrm{mV}$ or more, the experiment was not included in this analysis. 

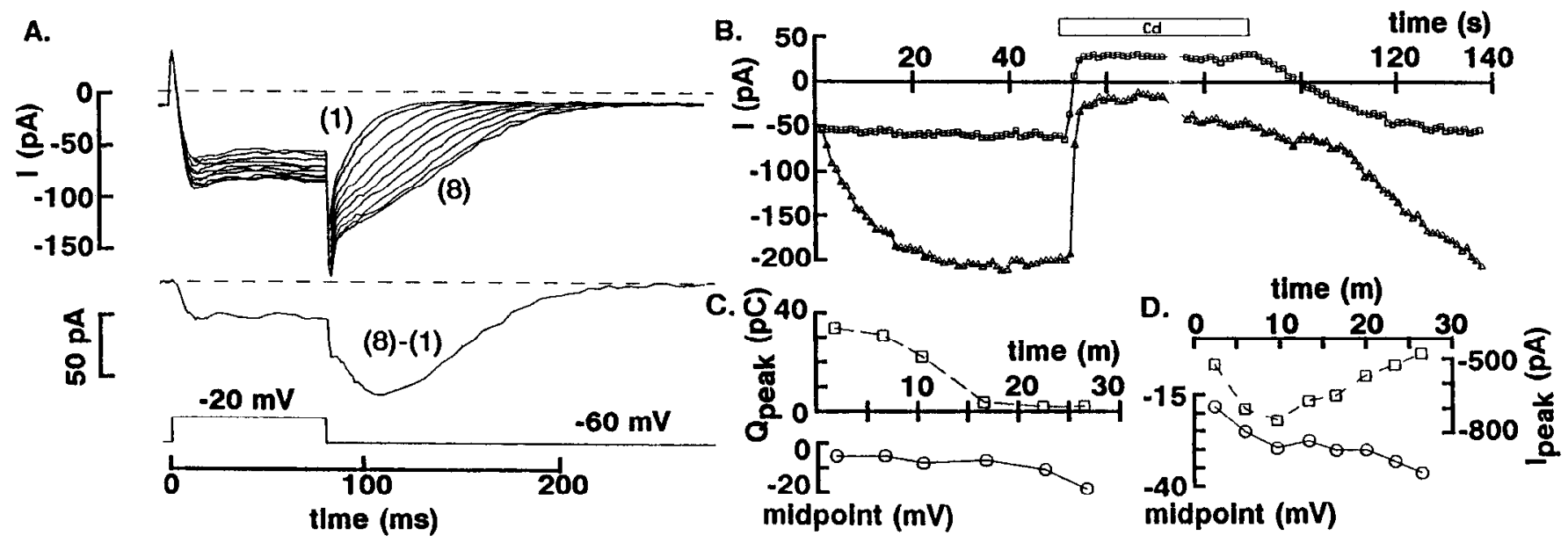

Figure 2. Temporal changes of $I_{\mathrm{CrCa}}$ and $I_{\mathrm{Ca}}$ at $\mathrm{pH}$ 7.40. A, Current buildup during repeating pulses in 3 mM Ca bath solution. Cone potential was stepped every $3 \mathrm{sec}$ from -60 to $-20 \mathrm{mV} 10$ times. Inward current of increasing magnitude was evoked during each step while the tail currents increased in both magnitude and duration. The "difference trace" below (last step applied minus first step) shows time course of current built up during step and underscores the increased duration of the tail currents. $B$, No calcium current buildup during rapid depolarizations; similar experiment as in $A$ except the step potential applied is $0 \mathrm{mV}$ (near $E_{\mathrm{Cl}}$ ), steps are applied more rapidly ( 1 per sec), and there are more of them. The squares are measurements of membrane current during the step to $0 \mathrm{mV}$ in $3 \mathrm{~mm} \mathrm{Ca}$ bath solution. Triangles plot tail currents measured isochronally $20 \mathrm{msec}$ after repolarization to $-60 \mathrm{mV}$. Block of currents during step and tail occurs during $100 \mu \mathrm{M}$ Cd ${ }^{2+}$ superfusion (duration shown by bar), and they recover with different time courses. Breaks in the lines connecting the symbols are where the depolarizations were stopped to measure the current-voltage relation (not shown), the actual duration of which was about 40 sec. Some increase in leakage current occurred during this time. $C$, Slow changes of chloride tail current with time in $3 \mathrm{~mm}$ Ca bath solution. On the upper vertical axis, $Q_{\text {peak }}$ (peak values of integrated tail current from $Q-V$ relations, as calculated in Fig. 1), plotted with squares, undergoes time-dependent reduction. Midpoint of Boltzmann fits to activation curves derived from $I_{\mathrm{CICa}}$ tail integrals (lower vertical axis, circles) becomes more negative with time as well. $D$, Slow changes of $\mathrm{Ba}^{2+}$ current in time. Barium currents were recorded with the CsCl pipette solution in a cone in $10 \mathrm{mM} \mathrm{Ba}^{2+}, 30 \mathrm{~mm}$ TEA bath at pH 7.40. Currentvoltage relations were obtained approximately every $3 \mathrm{~min}$, converted to activation curves, and fit with a Boltzmann function. Peak inward current (squares) rose during the first $10 \mathrm{~min}$, then declined, while the activation curve midpoint (circles) slowly drifted to more negative potentials.

\section{Bath pH changes strongly modulate the chloride current tail}

Our first measure of the $\mathrm{pH}$ dependence of the chloride tail current simply involved voltage clamping the membrane to -40 $\mathrm{mV}$, a value near the photoreceptor's normal dark resting potential, and briefly depolarizing to -20 or $-10 \mathrm{mV}$ to activate Ca channels. This typically generated a distinctive chloride tail current on repolarization to the holding potential that long outlived the faster decay of calcium current. Several such depolarizations, performed in bath solutions in which the $\mathrm{pH}$ was varied, are shown in Figure $3 A$. Following the decay of incompletely compensated capacitive artifacts, chloride tail current is seen at $\mathrm{pH} 7.4$ and 7.75 , but not at $\mathrm{pH} 6.92$. We isochronally measured the magnitude of chloride tail current in the different $\mathrm{pH}$ solutions to avoid contamination with calcium tail currents and capacitive currents. In other studies of cone photoreceptors as well as in the present work (see Figure $5 A$ ), it has been shown that calcium currents deactivate entirely within $10 \mathrm{msec}$ following repolarization (Maricq and Korenbrot, 1988; Barnes and Hille, 1989).

Figure $3 B$ shows an analysis performed on a cone as the $\mathrm{pH}$ was switched from 7.4 to $7.18,6.92$, and 7.75 . Values calculated by subtracting tail current from prepulse current show the decrease of chloride tail current in low $\mathrm{pH}$ and its pronounced increase in high $\mathrm{pH}$. In fact, near $\mathrm{pH} 7.75$ the chloride tail current at $-40 \mathrm{mV}$ typically became sustained following the step depolarization.

The results from six cells are compiled in Figure $3 C$. These data are all from cells held at $-40 \mathrm{mV}$ and stepped to -10 or $-20 \mathrm{mV}$ while being bathed in solutions of different $\mathrm{pH}$. Over the range of $\mathrm{pH}$ 6.6-8.2, a striking increase in tail current amplitude is seen. Since these measurements were made isochronally during the decay of tail current, much of the apparent increase is due to their slower decay, and not to an incrcasc in their peak magnitude, which in some cases became saturated.

\section{Ca channel activation midpoint is shifted by $\mathrm{pH}$}

We focus in this article on the notion that $\mathrm{pH}$-induced shifts in the Ca channel activation midpoint underlie the $\mathrm{pH}$ sensitivity of $I_{\mathrm{Cl}(\mathrm{Ca})}$. Here, we establish the $\mathrm{pH}$ sensitivity of the Ca channels since we will use this information to direct our later comparison with shifts in $I_{\mathrm{CICa}}$ activation.

Voltage-dependent activation of Ca channels of cone photoreceptors, like the $\mathrm{Ca}$ channels in many other cell types, is strongly affected by external $\mathrm{pH}$, as Figure 4 shows. A sample of currents evoked by depolarizing steps at one $\mathrm{pH}$ value (7.40) and a summary of $I-V$ relations for another cell made from currents recorded at four different $\mathrm{pH}$ values are shown in Figure 4, $A$ and $B$. Inward current is elicited at more negative potentials, and has a larger peak, in the bathing solution that is more basic than the $\mathrm{pH} 7.4$ control (Figure $4 B$ ). At more acidic $\mathrm{pH}$ values, inward currents are elicited only at more positive potentials and their peak magnitudes are smaller. For none of the $I-V$ curves is the reversal potential near $+50 \mathrm{mV}$ much changed. This result suggests that external $\mathrm{pH}$ influences the channel's gating mechanism and/or the local electric field acting upon it, leaving the reversal potential of current through the channel, determined by concentration gradients of permeant ions, unaltered.

The use of high concentrations of $\mathrm{Ba}^{2+}(10$ and $20 \mathrm{~mm})$ to enhance current flow in $\mathrm{Ca}$ channels has itself been shown to 

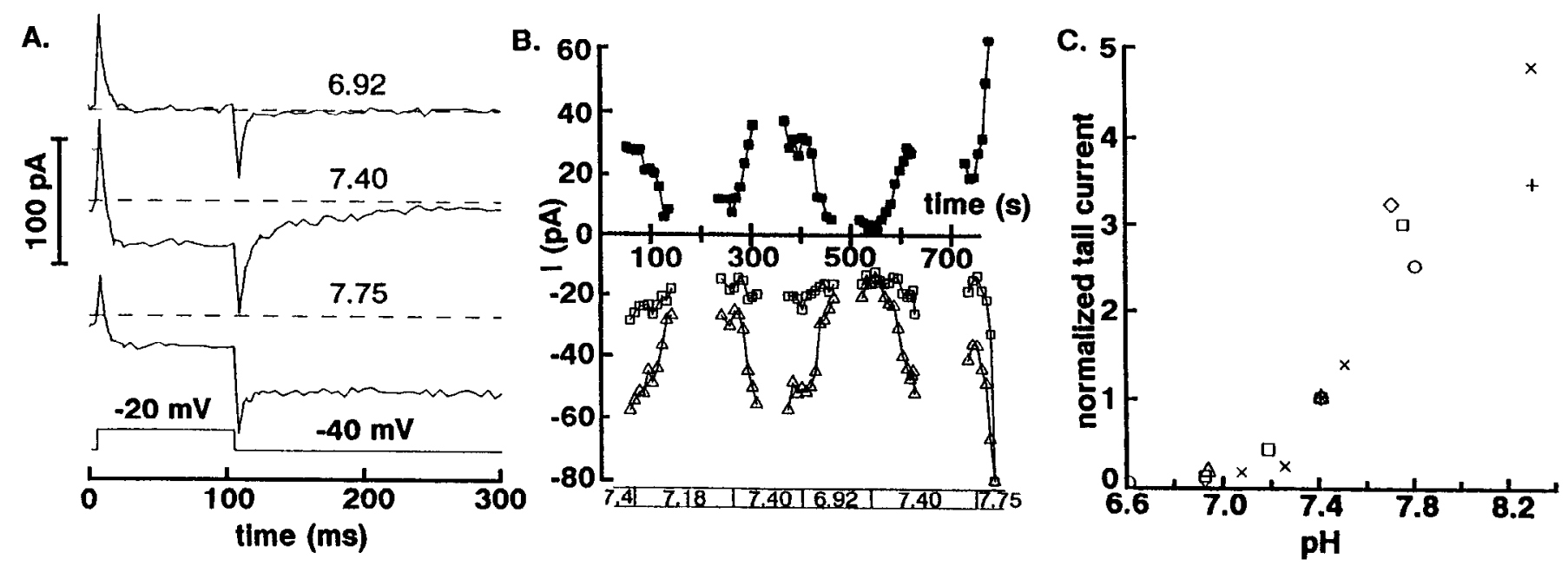

Figure 3. Modulation of $I_{\mathrm{Cl}(\mathrm{Ca})}$ by external pH changes. A, Current responses in a cone held at $-40 \mathrm{mV}$ and stepped to $-20 \mathrm{mV}$ for $100 \mathrm{msec}$ in $3 \mathrm{~mm}$ Ca bath solution adjusted to different $\mathrm{pH}$ values. Recording made at $\mathrm{pH} 7.40$ (middle) shows normal decay of tail current over $100 \mathrm{msec}$. At pH 6.92 (top), tail currents were absent, while at pH 7.75 (bottom), tail current activated by the step to $-20 \mathrm{mV}$ failed to decay after repolarization to $-40 \mathrm{mV}$. Capacitive currents were only partially compensated in this experiment. $B$, Bracketing of pH changes for tail current normalization at $\mathrm{pH}$ 7.4. Duration of exposure to each $\mathrm{pH}$ is shown by the boxes at the bottom (same cell and voltage protocol as in $A$ ). Plots of tail currents measured isochronally $20 \mathrm{msec}$ following steps from -20 to $-40 \mathrm{mV}$ every $9 \mathrm{sec}$ (triangles), current before each step at $-40 \mathrm{mV}$ (open squares), and difference currents (solid squares) are shown. Difference currents were generated by subtracting the tail current from the prepulse $(-40 \mathrm{mV}$ ) current; however, at $\mathrm{pH} 7.75$, where prepulse current became equal to tail current (the tail failed to decay), we used the average value of prepulse current measured just before the $\mathrm{pH}$ change in the subtraction. Recovery from $\mathrm{pH} 7.75$ was incomplete. $C$, Summary of pH-induced tail current modulation in $3 \mathrm{~mm}$ Ca bath solution, normalized to tail current in $\mathrm{pH} 7.40$. Each test $\mathrm{pH}$ was bracketed with exposures to pH 7.40 as shown in $B$ to minimize the effects of current rundown. Results from six cones shown with different symbols. Measurements from the cell illustrated in $A$ and $B$ are plotted here as squares.

shift channel activation for $\mathrm{Ca}$ (and other) channels positively along the voltage axis (Ohmori and Yoshii, 1977; Kostyuk et al., 1982; reviewed by Hille, 1984). In our experiments the control activation curve obtained in $20 \mathrm{mM} \mathrm{Ba}^{2+}$ at $\mathrm{pH} 7.40$ is probably shifted about $10 \mathrm{mV}$ in the positive direction relative to a calcium activation curve made at $3 \mathrm{mM} \mathrm{Ca}^{2+}$ (not shown). We are interested in relative shifts, however, and so after fitting each activation curve with a Boltzmann function, we plot the shift in the fit's midpoint relative to that obtained in $\mathrm{pH} 7.40$ in Figure $4 C$. Over the range from pH 6.2 to 8.2 , the midpoints undergo an $18 \mathrm{mV}$ shift. We also summarize the changes in peak current accompanying the shifts seen in different $\mathrm{pH}$ values in Figure $4 D$. The changes in peak current arc cxpressed rclativc to the peak current seen in $\mathrm{pH} 7.40$, which has been normalized. Over the range tested, the peak current changes threefold.

In both graphs (Fig. $4 C, D$ ), equations have been fit to the data. Both data sets were fit with lines (solid) as described in the figure caption, so that comparisons of slope could be made with analogous shifts in $I_{\mathrm{Cl}(\mathrm{Ca})}$ (see below). The midpoint shifts in Figure $4 C$ have also been fit with a polynomial (broken curve), which gives only a slightly better fit to the data over this voltage range.

\section{Chloride current pH sensitivity}

We now return to $\mathrm{pH}$-induced changes of $I_{\mathrm{Cl}(\mathrm{C})}$, measured with improved stimulus paradigms that facilitate comparison with $\mathrm{pH}$-induced changes of $I_{\text {Са }}$. Integrated tail current-prepulse voltage relations, like the one shown in Figure $1 B$, were examined with cclls hcld at $-60 \mathrm{mV}$ and bathcd in solutions of different $\mathrm{pH}$. Examples of currents measured under these conditions are shown in Figure $5 A$. These differ significantly from the currents measured at holding potentials of $-40 \mathrm{mV}$ (Fig. $3 A$ ) in that the tail current never becomes sustained at high $\mathrm{pH}$ and even a small tail can be evoked in low $\mathrm{pH}$ baths if the depolarizing step is made positive enough. In Figure $5 B$ we plot chargevoltage relations derived from these data by integrating the tail currents. We use integrated tail currents, not peak currents, for this analysis because information about $I_{\text {CI(Ca) }}$ is contained in both the magnitude and the duration of the tails. According to our simplifying assumptions, the magnitude and duration of chloride tail current reflect [Ca], which has been increased during the step and is now decreasing during the decay of tail current.

Saturation of the tail current magnitude occurs in some cases, especially immediatcly following largc calcium influxes. For example, in Figure $2 A$ our subtraction shows that as the presumed [Ca] $]_{i}$ buildup occurs and the tails get longer, the peak tail current immediately after the step saturates (the magnitude of the subtracted trace is smaller immediately following the voltage step). Saturation of the tail current might occur as the number of $\mathrm{Cl}$ channels activated approaches the total number of channels available. Since this occurs only around the peak of the $Q-V$ relation, we expect to underestimate the peak $Q-V$ value and to fit a Boltzmann function to the activation curve derived from the $Q-V$ relation whose midpoint would be more negative than if saturation had not occurred.

Notwithstanding these inadequacies, the chloride $Q-V$ relations were treated as if they were $I-V$ relations to obtain Boltzmann fits, described in Materials and Methods. Summaries of the $\mathrm{pH}$-induced shift in the Boltzmann-fit midpoints and peak $Q_{\mathrm{Cl}}$ values are presented in Figurc $5, C$ and $D$. These data sets were fit with lines, the slopes of which are given in the figure caption. In both cases considerable scatter resulted in large SEs for the best fit lines. The trend in the direction of both the peak 

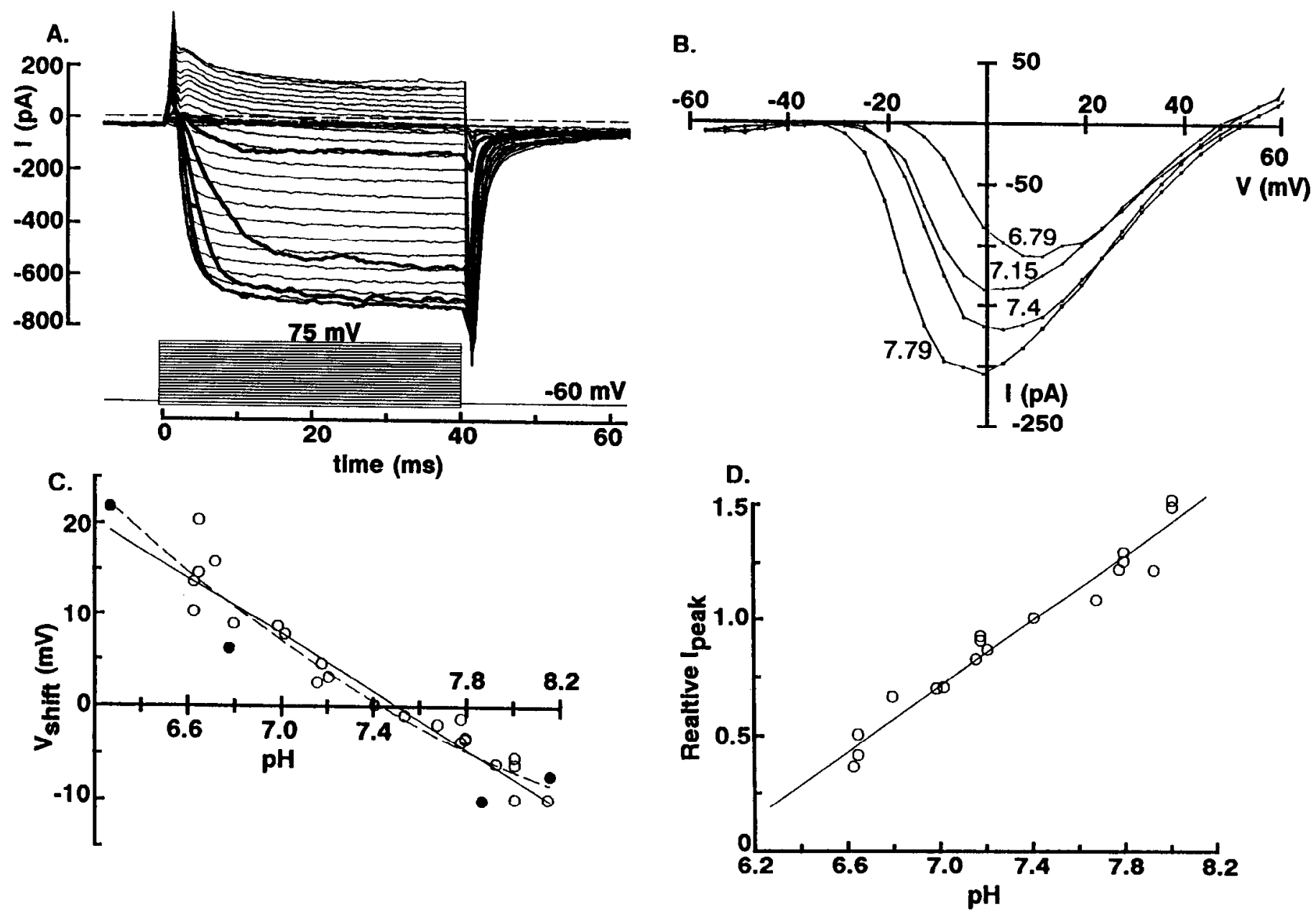

Figure 4. Shift in calcium and barium current activation and peak amplitude with changes in pH. $A$, Series of barium currents from a cone in $10 \mathrm{mM} \mathrm{Ba}{ }^{2+}$ at pH 7.40 in response to 35 depolarizing steps, each incremented by $4 \mathrm{mV}$, between -65 and $+75 \mathrm{mV}$ applied every 1 sec from a holding potential of $-60 \mathrm{mV}$. Current traces in response to steps to $-29,-25,-21$, and $-17 \mathrm{mV}$ are plotted with thicker lines for clarity. The data were filtered at $1 \mathrm{kHz}$ and sampled at $2 \mathrm{kHz}$. B. Barium current-voltage relations from a cone in $20 \mathrm{~mm} \mathrm{Ba}{ }^{2+}$ obtained at pH $6.79,7.15,7.40$, and 7.79. Currents were measured near the end of depolarizing steps lasting $80 \mathrm{msec}$ and are plotted here without leak correction. Corrections for time-dependent changes in peak current and Boltzmann-fit activation midpoint are not made in this figure, but we note that in this cell the midpoint measured in pH 7.4 changed from $-9 \mathrm{mV}$ at $362 \mathrm{sec}$ after breakthrough (shown here) to $-11 \mathrm{mV}$ at $923 \mathrm{sec}$ and to $-12 \mathrm{mV}$ at $1235 \mathrm{sec}$, while the last $I-V$ curve illustrated (7.15) was made at $1026 \mathrm{sec}$. Lines connect the dots. $C$, Summary of activation midpoint shifts in different pH values. The solid circles are from two cells in $3 \mathrm{mM} \mathrm{Ca}^{2+}$, and the open circles are from nine cells in 10 or $20 \mathrm{~mm} \mathrm{Ba}^{2+}$. The two curves are least-squares fits to the data. The solid line has a slope of $-15.5 \mathrm{mV} / \mathrm{pH}$ unit, and the broken line is a second-order polynomial given by $317-71(\mathrm{pH})+$ $3.81(\mathrm{pH})^{2}$, which gives a slightly better fit than the line. $D$. Summary of peak current changes in different $\mathrm{pH}$ values normalized to peak current in pH 7.4. Data are from nine cells in 10 or $20 \mathrm{~mm} \mathrm{Ba}{ }^{2+}$. The solid line is a least-squares fit with slope $0.71\left(\mathrm{pH}^{\mathrm{unit}}\right)^{-1}$. The fit obtained with a higher-order polynomial was nearly identical. Midpoint and peak shifts are relative to those in 7.4 , as each $I-V$ measurement was bracketed by measurements in $\mathrm{pH} 7.4$.

and midpoint shifts with changes of $\mathrm{pH}$ parallels the modifications seen in Ca channels (Fig. 4).

\section{Discussion}

We have examined effects of external $\mathrm{pH}$ on $I_{\mathrm{CA}}$ and $I_{\mathrm{C}(\mathrm{Ca})}$ in cone photoreceptors. As seen in the classical description of external $\mathrm{pH}$ actions on muscle chloride conductance (Hutter and Warner, 1967), we found chloride current to be strongly $\mathrm{pH}$ sensitive, becoming larger with increasing $\mathrm{pH}$. However, the increase in chloride conductance that we saw was due to a lengthening of the time course of chloride tail current decays rather than an increase in their magnitude. This observation led us to focus on underlying changes in $[\mathrm{Ca}]_{i}$ resulting from $\mathrm{pH}$-modified activation and permeation of $\mathrm{Ca}$ channels.

The characteristic slow chloride tail current decays seen fol- lowing calcium influx associated with step depolarizations presumably result as submembrane $[\mathrm{Ca}]_{i}$ is reduced by cellular buffering mechanisms, extrusion and diffusion. In many of the cells in which $I_{\mathrm{ClCa}}$ has been studied, prolonged depolarization or rapidly repeated depolarizations lead to slower tail current decays, indicating the link between $\mathrm{Cl}$ channel activation and $[\mathrm{Ca}]_{i}$, which may be markedly increased by these voltage-clamp paradigms. Here, in cones, we provide evidence that the time course of tail current decay depends on $\mathrm{Ca}^{2+}$ influx and consequently on $[\mathrm{Ca}]_{i}$ (Fig. 2), and we describe increases in tail current decay kinetics brought about by alkylinization of the bathing solution (Figs. 3, 5). Calcium currents become larger under these conditions (Fig. 4), supporting the possibility that the enhancement of tail currents occurs as a result of an increase in $[\mathrm{Ca}]_{i}$. 

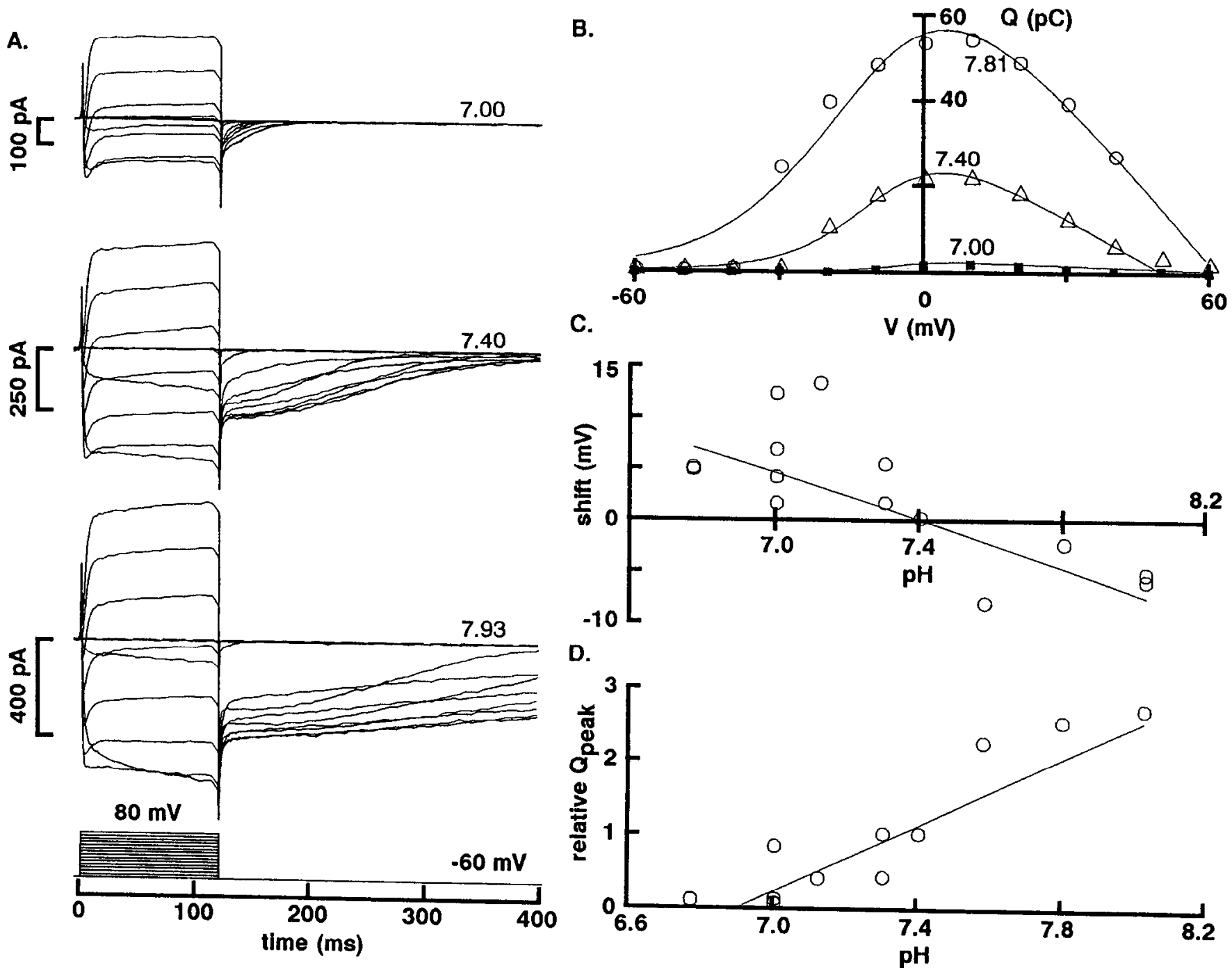

Figure 5. Analysis of pH-induced shifts in chloride tail currents measured in $3 \mathrm{~mm} \mathrm{Ca}$ bath solution. $A$, Representative current traces recorded at pH $7.00,7.40$, and 7.81 . The cone was held at $-60 \mathrm{mV}$ and depolarized for $120 \mathrm{msec}$ in 10 incrementing steps every 10 sec in each pH. $B$, Representative integrals of the chloride tail currents. The integrals were calculated by the method described in Figure 1. The solid lines are Boltzmann functions (from activation curve fits) multiplied by the "driving force" originally used to generate the activation curves (see Materials and Methods). $C$, Summary of shift in midpoint of Boltzmann functions fitted to chloride channel activation curves (derived from $Q-V$ relations from four cells). The solid line is a best fit to these data determined by a least-squares method and has a slope of $-11.5 \mathrm{mV} / \mathrm{pH} \mathrm{unit.} D$, Summary of shift in maximum value of chloride current integral from the same cells as in $C$. Measurements at different $\mathrm{pH}$ values in each cell were normalized to the value at $\mathrm{pH} 7.4$ in that cell. Least-squares fit line has slope of $2.25\left(\mathrm{pH}\right.$ unit) ${ }^{-1}$.

\section{Chloride current modulation by $\mathrm{pH}$}

Cytoplasmic [Ca] might be induced to increase or decrease by several mechanisms as the external $\mathrm{pH}$ is changed. One way to increase $[\mathrm{Ca}]_{i}$, focused upon in this report, is to increase loading of the cell by increasing calcium current flow. Other mechanisms might include (1) impairing calcium extrusion by $\mathrm{Na}-\mathrm{Ca}$ exchange, (2) modifying $\mathrm{Ca}^{2+}$ control of $\mathrm{Ca}^{2+}$ stores (requiring rapid internal $\mathrm{pH}$ changes), or (3) reducing EGTA $\mathrm{Ca}^{2+}$ buffering. None of these other possibilities is likely to be occurring here, however. $\mathrm{Na}-\mathrm{Ca}$ exchange would have been inhibited by the $100 \mathrm{mM} \mathrm{Cs}^{+}$used here internally (Schnetkamp et al., 1991), and the extracellular $\mathrm{pH}$ of HEPES-buffered media influences intracellular pH slowly (Curtin, 1986) and, with $10 \mathrm{~mm}$ internal HEPES, as used in our experiments, weakly (Krafte and Kass, 1988). Also, the ability of EGTA to buffer $\mathrm{Ca}^{2+}$ is reduced by decreasing pH (Caldwell, 1969), opposite to the reduction in $\mathrm{Ca}$-activated tail current seen here with decreasing $\mathrm{pH}$.

There could be direct effects of $\mathbf{p H}$ on the $\mathrm{Cl}$ channel. For example, hydroxyl ions might block the channel by competing with $\mathrm{Cl}^{-}$ions for binding sites, as may occur in oocytes where $I_{C(C) \text { a) }}$ is inhibited in solutions of $\mathrm{pH} 8$ or higher (Parker et al., 1985; Houamed, 1988). However, the highest $\mathrm{pH}$ we tested was 8.2 , and we saw increased, not smaller, tail currents. An interaction of HEPES itself with the $\mathrm{Cl}$ channel cannot be ruled out, as this $\mathrm{pH}$ buffer may inhibit Drosophila $\mathrm{Cl}$ channels at $\mathrm{pH} 7.0$ (Yamamoto and Suzuki, 1987).

Since the most striking features of $\mathrm{pH}$-induced modulation of $I_{\mathrm{C}(\mathrm{Ca})}$ are temporal, we have focused on $\mathrm{Cl}$ channel-gating changes rather than permeation changes. In addition to changes in $[\mathrm{Ca}]_{i}$ that most probably underlie the increased tail current time course, $\mathrm{pH}$ could alter the interaction between the $\mathrm{Cl}$ chan- 
nel and activating $\mathrm{Ca}^{2+}$ ions. Channel open times could be prolonged if high $\mathrm{pH}$ increased the binding affinity of the channel for $\mathrm{Ca}^{2+}$ via a transmembrane mechanism, resulting in slower decay of macroscopic current.

\section{Modification by pH of Ca channel activation and permeation}

The most direct way to alter [Ca], and one consistent with our findings, is to alter calcium currents. We have extended to cones the previous results from other cell types of strong $\mathrm{pH}$-induced changes in Ca channel activation and permeation (Ohmori and Yoshii, 1977; Iijima et al., 1986; Krafte and Kass, 1988; Prod'hom et al., 1989). Generally, shifts in the activation midpoint are accounted for by external $\mathrm{pH}$-induced changes in gating parameters of $\mathrm{Ca}$ channels, adequately described by considering changes of membrane surface potential caused by proton binding on the membrane surface, and interactions with the $\mathrm{Ca}$ channel protein that affect the channel voltage sensor (Ohmori and Yoshii, 1977; Iijima et al., 1986; Krafte and Kass, 1988). Permeation through Ca channels is also affected by external $\mathrm{pH}$, again described by interactions between protons and the membrane and the channel protein that effectively reduce [Ca] at the surface of the membrane and near the mouth of the pore (Ohmori and Yoshii, 1977; Iijima et al., 1986) or that involve block of the Ca channel by protons (Hess et al., 1986; Krafte and Kass, 1988; Prod'hom et al., 1989). Our results are quantitatively similar to those described for L-type channels in rat cardiac ventricular cells (Krafte and Kass, 1988).

\section{Comparison of calcium influx and chloride tail current}

Our approach has been to relate integrated chloride tail currents to calcium currents with simple assumptions: Ca channels do not inactivate during the depolarizing pulse, chloride current flowing prior to the tail (during the test steps) is small, and contributions to the tail integral from calcium tail currents and chloride currents activated by the brief calcium tail current are also small. Approximated by linear fits, we compared the voltage shifts in the $\mathrm{Cl}$ channel activation curve midpoint and $Q-V$ relation peak with the analogous shifts we found for Ca channel activation curves and $I-V$ relation peaks.

Shifts in the Ca channel activation midpoint occurred over the $\mathrm{pH}$ range of $6.1-8.2$, with a slope of $-15.5 \mathrm{mV}$ per $\mathrm{pH}$ unit, a value nearly identical with previous results (Krafte and Kass, 1988). Over a slightly narrower $\mathrm{pH}$ range (6.8-8.0), we recorded shifts in $I_{\mathrm{Cl}(\mathrm{Ca})}$ activation with a slope of $-11.5 \mathrm{mV}$ per $\mathrm{pH}$ unit. We are cautious in interpreting this comparison because of the large degree of scatter in the chloride current data, but these values are close enough to suggest that the shift in $\mathrm{Cl}$ channel activation could be accounted for by the shift in underlying $\mathrm{Ca}$ channel activation.

Changes in normalized peak calcium current as a function of $\mathrm{pH}$ occur with a slope of 0.71 per $\mathrm{pH}$ unit. Changes in integrated chloride tail current as a function of $\mathrm{pH}$ occur with a slope of 2.25 per $\mathrm{pH}$ unit. The relation between these slopes, simply a factor of 3 , might suggest a $\mathrm{Cl}$ channel-gating scheme in which several $\mathrm{Ca}^{2+}$ ions are required for $\mathrm{Cl}$ channel activation.

Our initial view of $\mathrm{pH}$-induced $I_{\mathrm{Cl}(\mathrm{Ca})}$ modulation came from experiments such as those in Figure 3 where, by a simple analysis paradigm, $\mathrm{pH}$ appeared to have enormous influence over $I_{\mathrm{Cl}(\mathrm{Ca})}$. In terms of the shift in Ca channel activation and permeation induced by $\mathrm{pH}$ we can easily interpret those data. Voltage clamping the cone membrane near $-40 \mathrm{mV}$ and stepping to $-20 \mathrm{mV}$ would, at control $\mathrm{pH}$, give rise to modest chloride tail currents.
In more acidic solutions, the membrane potential step to -20 $\mathrm{mV}$ would activate very little $I_{\mathrm{Ca}}$ and, subsequently, little $I_{\mathrm{Cl}(\mathrm{Ca})}$. Under more basic conditions, even holding the membrane at $-40 \mathrm{mV}$ would activate significant $I_{\mathrm{Ca}}$ and, as this potential was maintained and $\mathrm{Ca}$ channels did not inactivate, shortly lead to large increases in $[\mathrm{Ca}]_{i}$ that would give large, sustained chloride "tail" currents. This interpretation qualitatively accounts for $\mathrm{pH}$ modulation of $I_{\mathrm{CI}(\mathrm{Ca})}$.

\section{Physiological consequences of $\mathrm{pH}$-induced $\mathrm{Ca}$ channel changes}

$I_{\mathrm{C}(\mathrm{Ca})}$ in neurons generally is considered to have a role in stabilizing membrane potential and has been shown to underlie Ca action potential repolarization in cones (Maricq and Korenbrot, 1988). In cone photoreceptor function, $I_{\mathrm{CI}(\mathrm{Ca})}$ may also have a significant role in mediating the effects of synaptic feedback from horizontal cells (Baylor et al., 1971), which could underlie inhibitory lateral interactions (O'Bryan, 1973; Lasansky, 1981; Burkhardt et al., 1988). Thus, modulation of $I_{\mathrm{Cl}(\mathrm{Ca})}$ by $\mathrm{pH}$ may play a role in cone function, but underlying the $\mathrm{pH}$ dependence of $I_{\mathrm{Cl}(\mathrm{Ca})}$ are changes in the properties of $\mathrm{Ca}$ channels that could be more significant. In this section we examine other consequences of $\mathrm{pH}$-induced changes of calcium channel properties.

Suggestions that photoreceptors release transmitter via both calcium-dependent and calcium-independent mechanisms (Miller and Schwartz, 1983; Schwartz, 1986, 1987) seemed to provide a solution to the apparent mismatch between the photoreceptor operating range and calcium current activation range. Photoreceptors, at rest in the dark near $-40 \mathrm{mV}$, may be hyperpolarized by light to membrane potentials as negative as -70 $\mathrm{mV}$ (Baylor et al., 1984). Several reports suggest that photoreceptors express L-type Ca channels (Maricq and Korenbrot, 1988; Barnes and Hille, 1989; Ahlijanian et al., 1990) and have calcium currents that activate at potentials more positive than $-45 \mathrm{mV}$ (Bader et al., 1982; Corey et al., 1984; Maricq and Korenbrot, 1988; Barnes and Hille, 1989). Thus, there were potentials (from $-45 \mathrm{mV}$ and more negative) over which very few $\mathrm{Ca}$ channels would be activated, and subsequently, transmitter release either must be mediated by $\mathrm{Ca}$ channels other than those described or Ca-independent mechanisms operate in this range.

Perhaps neither additional Ca channel types nor Ca-independent mechanisms need to be invoked to explain transmitter release from photoreceptors. First, it has been shown that photoreceptor synaptic output is limited to a range of about $5 \mathrm{mV}$, that being from the dark potential and more negative (Attwell et al., 1987; Belgum and Copenhagen, 1988). Second, as a consequence of our study, we see that the voltage range over which $\mathrm{Ca}$ channels activate in cones can be shifted by external $\mathrm{pH}$. All of the studies of calcium current activation in rods and cones were performed at or slightly below pH 7.4 (Bader et al., 1982; Corey et al., 1984; Maricq and Korenbrot, 1988; Barnes and Hille, 1989). However, measurements of photoreceptor synaptic output in superfused preparations have been made variously at pH 7.8 (Belgum and Copenhagen, 1988), 7.7 (Wu, 1985), 7.6 (Attwell et al., 1987), and 7.4 (Miller and Schwartz, 1983; Schwartz, 1986, 1987). If transmitter release is Ca dependent, then these measurements are sensitive to the $\mathrm{pH}$-affected range of Ca channel activation, and comparisons between the separate studics or of their relation to measured calcium activation curves ought to consider the pronounced $\mathrm{pH}$ sensitivity of $\mathrm{Ca}$ channels. Measurement of $\mathrm{pH}$ in the subretinal space surrounding the photoreceptors suggests that this value is between 7.0 and 7.2 
(Oakley and Wen, 1989). Our results would suggest that at pH 7.0 there would be little overlap between the Ca channel activation range and the normal operating range of photoreceptors, whereas at $\mathrm{pH} 7.8, \mathrm{Ca}$ channel activity would be much more strongly modulated by membrane potential within the normal photoreceptor operating range.

If the $\mathrm{pH}$ surrounding the photoreceptors (or any cells) were to change, Ca channel activity could be changed as well, and this might lead, for example, to dynamic modulation of calciumdependent transmitter release. External pH changes, on the order of 0.01 to $0.03 \mathrm{pH}$ units, have been shown to occur in the retina with prolonged illumination (Borgula et al., 1989), but our results indicate that this minor alkylinization of the subretinal space would alter $\mathrm{Ca}$ channel activation in a negligible manner. Larger $\mathrm{pH}$ changes accompanying pathophysiological conditions such as hypoxia could have strong effects on calciumdependent functions in neurons and other cells.

\section{References}

Ahlijanian MK, Westenbroek RE, Catterall WA (1990) Subunit structure and localization of dihypropyridine-sensitive calcium channels in mammalian brain, spinal cord and retina. Neuron 4:819-832.

Attwell D, Borges S, Wu SM, Wilson M (1987) Signal clipping by the rod output synapse. Nature 328:522-524.

Bader CR, Bertrand D, Schwartz EA (1982) Voltage-activated and calcium-activated currents studied in solitary rod inner segments from the salamander retina. J Physiol (Lond) 331:253-284.

Barnes S, Bui Q (1990) Modulation of calcium-activated chloride current in cone photoreceptors with changes of external pH. Soc Neurosci Abstr 16:406.

Barnes S, Hille B (1989) Ionic channels of the inner segment of tiger salamander cone photoreceptors. J Gen Physiol 94:719-743.

Barrett JN, Magleby KL, Pallotta BS (1982) Properties of single calcium-activated potassium channels in cultured rat muscle. J Physiol (Lond) 331:211-230.

Baylor DA, Funrtes MGF, O'Bryan PM (1971) Receptive fields of cones in the retina of the turtle. J Physiol (Lond) 214:265-294.

Baylor DA, Matthews G, Nunn BJ (1984) Location and function of voltage-sensitive conductances in retinal rods of the salamander, $\mathrm{Am}$ bystoma tigrinum. J Physiol (Lond) 354:203-223.

Belgum JH, Copenhagen DR (1988) Synaptic transfer of rod signals to horizontal and bipolar cells of the retina of the toad (Bufo marinus). J Physiol (Lond) 396:225-245.

Borgula GA, Karwoski CJ, Steinberg RH (1989) Light-evoked changes in extracellular $\mathrm{pH}$ in frog retina. Vision Kes 29:1069-1077.

Burkhardt DA, Gottesman J, Thoreson WB (1988) Prolonged depolarization in turtle cones evoked by current injection and stimulation of the receptive field surround. J Physiol (Lond) 407:329-348.

Caldwell PC (1969) Calcium chelation and buffers. In: A symposium on calcium and cellular function (Cuthbert $A W$, ed), pp 10-16. New York: St. Martins.

Corey DP, Dubinsky JM, Schwartz EA (1984) The calcium current in inner segments of rods from the salamander (Ambystoma tigrinum) retina. J Physiol (Lond) 354:557-575.

Curtin NA (1986) Buffer power and intracellular $\mathrm{pH}$ of frog sartorius muscle. Biophys J 50:837-841.

Evans MG, Marty A (1986) Calcium-dependent chloride currents in isolated cells from rat lacrimal gland. J Physiol (Lond) 378:437-460.

Hess P, Lansman JB, Tsien RW (1986) Calcium channel selectivity for divalent and monovalent cations. Voltage and concentration de- pendence of single channel current in ventricular heart cells. J Gen Physiol 88:293-319.

Hille B (1984) Ionic channels of excitable membranes. Sunderland, MA: Sinauer.

Houamed K (1988) Electrophysiological comparison of some ion channels synthesized following microinjection of brain-derived messenger ribonucleic acid in Xenopus laevis oocytes. PhD Thesis, University of London.

Hutter OF, Warner AE (1967) The pH sensitivity of the chloride conductance of frog skeletal muscle. J Physiol (Lond) 189:403-425.

Iijima T, Ciani S, Hagiwara S (1986) Effects of the external pH on Ca channels: experimental studies and theoretical considerations using a two-site, two ion model. Proc Natl Acad Sci USA 83:654-658.

Kaibara M, Kameyama M (1988) Inhibition of calcium channel by intracellular protons in single ventricular myocytes of the guinea-pig. J Physiol (Lond) 403:621-640.

Korn SJ, Horn R (1989) Influence of sodium-calcium exchange on calcium current rundown and the duration of calcium-dependent chloride currents in pituitary cells, studied with whole cell and perforated patch recording. J Gen Physiol 94:789-812.

Kostyuk PG, Mironov SL, Doroshenko PA, Ponomarev VN (1982) Surface charges on the outer side of mollusc neuron membrane. J Membr Biol 76:83-93.

Krafte DS, Kass RS (1988) Hydrogen ion modulation of Ca channel current in cardiac ventricular cells. J Gen Physiol 91:641-657.

Lasansky A (1981) Synaptic action mediating cone responses to annular illumination in the retina of the larval tiger salamander. J Physiol (Lond) 310:205-214.

Lukacs GL, Moczydlowski E (1990) A chloride channel from lobster walking leg nerves: characterization of single channel properties in planar bilayers. J Gen Physiol 96:707-733.

Maricq AV, Korenbrot JI (1988) Calcium and calcium-dependent chloride currents generate action potentials in solitary cone photoreceptors. Neuron 1:503-515.

Miller AM, Schwartz EA (1983) Evidence for the identification of synaptic transmitters released by photoreceptors of the toad retina. J Physiol (Lond) 334:325-349.

Oakley B II, Wen R (1989) Extracellular pH in the isolated retina of the toad in darkness and during illumination. J Physiol (Lond) 419: 353-378.

O'Bryan PM (1973) Properties of the depolarizing synaptic potential evoked by peripheral illumination in cones of the turtle retina. $J$ Physiol (Lond) 235:207-223.

Ohmori H, Yoshii M (1977) Surface potential reflected in both gating and permeation mechanisms of sodium and calcium channels of the tunicate egg cell membrane. J Physiol (Lond) 267:429-463.

Parker I, Gunderson CB, Miledi R (1985) A transient inward current elicited by hyperpolarization during serotonin activation in Xenopus oocytes. Proc R Soc Lond [Biol] 223:279-292.

Prod'hom B, Pietrobon D, Hess $P$ (1989) Interactions of protons with single open L-type calcium channels: location of protonation site and dependence of proton-induced current fluctuations on concentration and species of permeant ion. J Gen Physiol 94:23-42.

Schnetkamp PPM, Szerencsei RT, Basu DK (1991) Unidirectional $\mathrm{Na}^{+}, \mathrm{Ca}^{2+}$ and $\mathrm{K}^{+}$fluxes through the bovine rod outer segment $\mathrm{Na}-$ Ca-K exchanger. J Biol Chem 266:198-206.

Schwartz EA (1986) Synaptic transmission in amphibian retinae during conditions unfavorable for calcium entry into presynaptic terminals. J Physiol (Lond) 376:411-428.

Schwartz EA (1987) Depolarization without calcium can release gamma-amino butyric acid from a retinal neuron. Science 238:350-355.

Yamamoto D, Suzuki N (1987) Blockage of chloride channels by HEPES buffer. Proc R Soc Lond [Biol] 230:93-100.

Wu SM (1985) Synaptic transmission from rods to bipolar cells in the tiger salamander retina. Proc Natl Acad Sci USA 82:3944-3947. 